\title{
JOGO DE TABULEIRO: UMA METODOLOGIA LÚDICA PARA O ENSINO DE GEOGRAFIA
}

\author{
Raiane Florentino $^{1}$
}

Resumo: $O$ artigo apresenta a experiência com o jogo de tabuleiro ao longo da oficina, ministrada no Encontro Lívia de Oliveira: Cartografia Escolar e Ensino de Geografia. Este jogo de tabuleiro é indicado para as turmas da $1^{\text {a }}$ série do ensino médio, pois abrange diversos temas da Geografia inseridos no ensino fundamental, sendo considerado, então, como um material diagnóstico das séries anteriores. Pelos resultados obtidos, pode-se destacar que, através das peças deste lúdico, como as cartas, são fornecidos subsídios para a exploração e compreensão dos fenômenos do espaço geográfico, assim como, também, das representações gráficas, como os mapas temáticos. Somado a isso, este lúdico proporciona benefícios para o processo de ensino-aprendizagem, como: a aceitação das regras; o desenvolvimento da atenção, do planejamento, do raciocínio; a fixação dos conteúdos; além de possibilitar trabalhar a ansiedade e a competitividade de forma espontânea e construtiva.

Palavras chave: Ensino de Geografia. Jogo de tabuleiro. Lúdico.

\section{BOARD GAME: A LODIC METHODOLOGY FOR THE TEACHING OF GEOGRAPHY}

\begin{abstract}
The article presents the experience with the board game during the short course, taught at the Lívia de Oliveira Meeting: School Cartography and Geography Teaching. This board game is indicated for the classes of the first grade of high school, since it covers several subjects of the Geography inserted in the fundamental education, being considered, then, like a diagnostic material of the previous series. From the results obtained, it is possible to emphasize that, through the pieces of this play, such as the letters, are provided subsidies for the exploration and understanding of the phenomena of geographic space, as well as, also, of graphic representations, such as thematic maps. Added to this, this playful provides benefits to the teaching-learning process, such as: acceptance of the rules; the development of attention, planning, reasoning; the fixation of contents; in addition to making it possible to work with anxiety and competitiveness spontaneously and constructively. Keywords: Teaching Geography. Board game. Playful.
\end{abstract}

1 Geógrafa (UNESP, Campus de Ourinhos) e Mestre em Geografia (Instituto de Geociências e Ciências Exatas, UNESP, Campus de Rio Claro). E-mail: raianeflorentino@gmail.com

Estudos Geográficos, Rio Claro, 16(1): 144-158, jan./jun. 2018 (ISSN 1678—698X) 


\section{INTRODUÇÃO}

O presente artigo expõe a experiência do minicurso sobre o Jogo das Questões Geográficas, no Encontro Lívia de Oliveira: Cartografia Escolar e Ensino de Geografia, ministrado na UNESP, Campus de Rio Claro.

No decorrer do curso, apresentaram-se reflexões sobre o uso do lúdico em sala de aula, explorando a eficiência do material ao auxiliar o professor na aplicação dos conteúdos da disciplina de Geografia, baseados na Proposta Curricular do Estado de São Paulo (PCESP).

Deste modo, o jogo abrange os temas inseridos nos anos finais do ensino fundamental, sendo indicado, então, para as turmas da $1^{\text {a }}$ série do ensino médio, compondo, portanto, um material paradidático diagnóstico das séries anteriores.

O público-alvo deste curso foram professores da rede básica de ensino e alunos de licenciatura em Geografia da instituição.

Para dar início a discussão, serão apontados os elementos da pesquisa de mestrado $^{2}$ que culminaram na elaboração deste lúdico, exibindo-se, assim, os referenciais teóricos e metodológicos utilizados na elaboração do protótipo.

Como linha de raciocínio, adotou-se a pesquisa qualitativa, apropriando-se do método "Estudo de Caso", baseado nas técnicas e nos procedimentos extraídos de Yin (2001), que apresenta no livro Estudo de Caso: Planejamento e Métodos orientações e diversos exemplos sobre o seu uso.

O autor afirma que é necessário obter, primeiramente, um projeto de pesquisa, para, em seguida, colher e analisar os dados e, finalmente, compartilhar os resultados por meio da redação final.

Ao relacionar esses apontamentos com a pesquisa em questão, estabeleceram-se, inicialmente, o objetivo e o objeto de estudo: realizar a reflexão sobre o uso do jogo de tabuleiro no ensino de Geografia, almejando promover o desenvolvimento e a assimilação do conteúdo, de maneira que o aluno habilite sua linha de raciocínio próprio.

Feito isso, efetuou-se o levantamento bibliográfico para sustentar a hipótese deste estudo, que defende o jogo como um material paradidático lúdico que contribui no processo de ensino-aprendizagem.

Os temas abordados nesta investigação foram: ensino (o uso do jogo no ensino, a psicologia do desenvolvimento cognitivo infantil e o papel docente na mediação do jogo em sala de aula); e cartografia (mapas temáticos, semiologia gráfica, cartografia escolar e alfabetização cartográfica).

No que tange as bibliografias a respeito do uso do jogo no ensino, verificouse, através dos relatos das experiências de diversos pesquisadores de áreas distintas, como Rosa (2004), Lopes (2007), Villas Bôas (2007), Marcato (2009), Santana (2012), Sdoukos (2012), Miani (2013), Franco (2014), Soukeff (2014), Silva (2014), entre outros, que o educador pode se apropriar de recursos paradidáticos, como o jogo de tabuleiro, para buscar uma melhor compreensão de temas, até mesmo os tidos como de difícil compreensão.

2.Dissertação de mestrado de Raiane Florentino, intitulada "O USO DE JOGOS DIDÁTICOS EM SALA DE AULA: REFLEXÕES SOBRE A MEDIAÇÃO DO ENSINO DA CARTOGRAFIA TEMÁTICA NA DISCIPLINA DE GEOGRAFIA NO ENSINO FUNDAMENTAL II", orientada pela Profa. Dra. Andréa Ap. Zacharias, defendida em 27 de setembro de 2016.

Estudos Geográficos, Rio Claro, 16(1): 144-158, jan./jun. 2018 (ISSN 1678—698X) 
Para tanto, autores como Chateau (1954; 1987) e Gottardi (2009) demonstram em suas obras a influência que o jogo possui no processo de construção e desenvolvimento cognitivo, sendo um elemento de extrema importância a ser explorado, principalmente, na infância.

Ao encontro disso, Jacquin (1960; 1963); Macedo, Petty e Passos (2005) e Lopes (2007) enfatizam como é possível obter qualidade no ensino se o jogo for utilizado como um recurso paralelo aos materiais didáticos, como o livro e a lousa.

Tais autores, através de suas pesquisas, explicitam o quanto esse lúdico é um agente facilitador que pode contribuir para o ambiente escolar, podendo ser um grande aliado do professor em sala de aula.

Após a consulta das obras supracitadas, entre outras, efetuou-se a coleta das bases de dados. Foram aplicados questionários e entrevistas verbais informais com os professores da rede pública de ensino, feitos na sondagem inicial do projeto. Isso permitiu explorar o conhecimento desses profissionais acerca do tema, além de conhecer as técnicas e dinâmicas utilizadas na aplicação do conteúdo de Geografia em sala de aula.

Diante disso, foram escolhidos os assuntos para a elaboração do jogo protótipo, com o princípio de trabalhar questões de difícil entendimento para 0 professor e, consequentemente, para o aluno.

Primeiramente, o material foi aplicado em quatro escolas: duas situadas no município de Rio Claro-SP e duas em São José dos Campos-SP; onde, no decorrer da atividade, observou-se o comportamento da turma diante do material. Ao final da ação, aplicou-se um questionário requisitando a opinião e sugestão do responsável pela classe a respeito do protótipo.

Com base nessa crítica, o protótipo foi aprimorado e adequado, para que, posteriormente, fosse apresentado em cursos e oficinas, como é o caso em questão. Sendo assim, este artigo irá apresentar como o lúdico foi elaborado, a aplicação do mesmo nas escolas e, também, no minicurso.

$\mathrm{Na}$ aplicação do jogo, tanto na escola quanto na oficina, verificou-se a eficiência do material, observando como os participantes interagiam e as dúvidas que surgiram no decorrer da prática. Além disso, solicitou-se uma análise do mesmo após a dinâmica, onde foram sugeridas ideias para melhorar e adequar o lúdico.

Em suma, baseando-se nos resultados obtidos, foi possível concluir que o uso do jogo de tabuleiro foi eficaz no processo de ensino-aprendizagem de Geografia, tendo em vista que ajuda a relembrar conceitos e, assim, auxilia o professor a conquistar alternativas para trabalhar os conteúdos em sala de aula, além de apresentar, também, uma possibilidade lúdica de ensinar e aprender de forma divertida, contribuindo, então, para a fixação dos conteúdos.

Portanto, constata-se que o jogo de tabuleiro é um grande parceiro do educador no ambiente escolar, sendo um material paradidático bem visto e recebido, principalmente, pelos estudantes. Contudo, o material só será eficiente se houver o direcionamento e a coordenação do profissional de ensino em todas as etapas.

\section{A ELABORAÇÃO DO JOGO}


Para a elaboração do material paradidático, foi de extrema importância a leitura e análise das bases curriculares de ensino. No Brasil, o documento principal chama-se Parâmetros Curriculares Nacionais (PCN).

Os PCN apresentam meios de como trabalhar e desenvolver com os alunos competências e habilidades importantes para compreender e entender a Geografia.

Tais conteúdos abordam noções de espaço; estudos sociais; leis sobre o tempo e a natureza; relações entre os eventos geográficos em diferentes escalas; leitura, elaboração e interpretação de mapas e cartas; diferenciação das paisagens e o que as caracterizam; entre outras.

No Quadro 1, encontram-se os objetivos gerais, segundo os PCN, para a disciplina Geografia, que auxiliaram na elaboração do jogo em questão.

\section{QUADRO 1 - Objetivos gerais de Geografia nos PCN}

\begin{tabular}{|c|c|}
\hline Objetivos & Conceitos \\
\hline $\begin{array}{c}\text { Conhecer o mundo atual em sua diversidade, favorecendo a } \\
\text { compreensão, de como as paisagens, os lugares e os territórios se } \\
\text { constroem. }\end{array}$ & $\begin{array}{l}\text { Diversidade; Paisagem; Lugar; } \\
\text { Território; Representações. }\end{array}$ \\
\hline $\begin{array}{c}\text { Identificar e avaliar as ações dos homens em sociedade e suas } \\
\text { consequências em diferentes espaços e tempos, de modo a construir } \\
\text { referenciais que possibilitem uma participação propositiva e reativa nas } \\
\text { questões socioambientais locais. }\end{array}$ & $\begin{array}{l}\text { Sociedade; Participação relativa; } \\
\text { Questões socioambientais; } \\
\text { Apropriação do espaço; Estudos } \\
\text { sociais. }\end{array}$ \\
\hline $\begin{array}{c}\text { Conhecer o funcionamento da natureza em suas múltiplas relações, de } \\
\text { modo a compreender o papel das sociedades na construção do território, } \\
\text { da paisagem e do lugar. }\end{array}$ & $\begin{array}{l}\text { Natureza; Relações; Apropriação do } \\
\text { espaço; Estudos sociais. }\end{array}$ \\
\hline $\begin{array}{l}\text { Compreender a espacialidade e temporalidade dos fenômenos } \\
\text { geográficos estudados em suas dinâmicas e interações. }\end{array}$ & $\begin{array}{l}\text { Fenômenos geográficos; Interações; } \\
\text { Dinâmicas espaciais. }\end{array}$ \\
\hline $\begin{array}{l}\text { Compreender que as melhorias nas condições de vida, os direitos } \\
\text { políticos, os avanços tecnológicos e as transformações socioculturais são } \\
\text { conquistas ainda não usufruídas por todos os seres humanos e, dentro de } \\
\text { suas possibilidades, empenhar-se em democratizá-las. }\end{array}$ & $\begin{array}{l}\text { Direitos políticos; Tecnologia; } \\
\text { Apropriação desigual; Divisão do } \\
\text { trabalho; Capitalismo. }\end{array}$ \\
\hline $\begin{array}{c}\text { Conhecer e saber utilizar procedimentos de pesquisa da Geografia para } \\
\text { compreender a paisagem, o território e o lugar, seus processos de } \\
\text { construção, identificando suas relações, seus problemas e suas } \\
\text { contradições. }\end{array}$ & $\begin{array}{l}\text { Paisagem; Território; Lugar; } \\
\text { Dinâmicas do espaço. }\end{array}$ \\
\hline $\begin{array}{l}\text { Orientar a compreender a importância das diferentes linguagens na leitura } \\
\text { da paisagem, desde imagens, música e literatura de dados e de } \\
\text { documentos de diferentes fontes de informação, de modo a interpretar, } \\
\text { analisar e relacionar informações sobre o espaço. }\end{array}$ & $\begin{array}{l}\text { Linguagens; Representações } \\
\text { cartográficas. }\end{array}$ \\
\hline $\begin{array}{l}\text { Saber utilizar a linguagem gráfica para obter informações e representar a } \\
\text { espacialidade dos fenômenos geográficos. }\end{array}$ & $\begin{array}{l}\text { Linguagens; Representações } \\
\text { cartográficas. }\end{array}$ \\
\hline $\begin{array}{l}\text { Valorizar o patrimônio sociocultural e respeitar a sociodiversidade, } \\
\text { reconhecendo-os como direitos dos povos e indivíduos, sendo elementos } \\
\text { de fortalecimento da democracia. }\end{array}$ & $\begin{array}{l}\text { Sociedade; Democracia; } \\
\text { Cultura local. }\end{array}$ \\
\hline
\end{tabular}

Como complemento aos PCN, o Estado de São Paulo apresenta um currículo específico para o ensino oferecido pelas escolas estaduais, denominado de Proposta Curricular do Estado de São Paulo (PCESP). Este documento é utilizado pelo professor ao incorporar o papel de mediador do conhecimento em sala de aula.

Baseado na leitura desta proposta e no pensamento de Castellar (2006), é possível afirmar que os currículos ainda precisam sofrer muitas transformações, e é necessário que o ensino de Geografia supere as aprendizagens repetitivas e invista nas análises, interpretações e aplicações em situações práticas, como o sugerido 
neste artigo através do jogo de tabuleiro.

Sendo assim, a proposta do jogo tabuleiro vai ao encontro desta reflexão e destaca-se, também, pela observação feita por Lopes (2002) sobre como este tipo de jogo contribui para o indivíduo aceitar regras e limites; desenvolver a atenção, o planejamento, o raciocínio; a fixação dos conteúdos; a avaliação; trabalhar a ansiedade e a competitividade.

Como consequência disso, o jogo foi elaborado através dos softwares de artes gráficas: Inkscape e GIMP; e apresenta desafios aos estudantes, uma vez que envolve perguntas e respostas sobre diversos conteúdos da Geografia, possibilitando alto grau de raciocínio sobre Geopolítica, Cartografia, Geologia, Meio Ambiente, Recursos Hídricos, Continentes, Economia, Biodiversidade, Regiões Brasileiras, entre outros, numa proposta holística e sistêmica.

\section{FIGURA 1 - Jogo de tabuleiro}

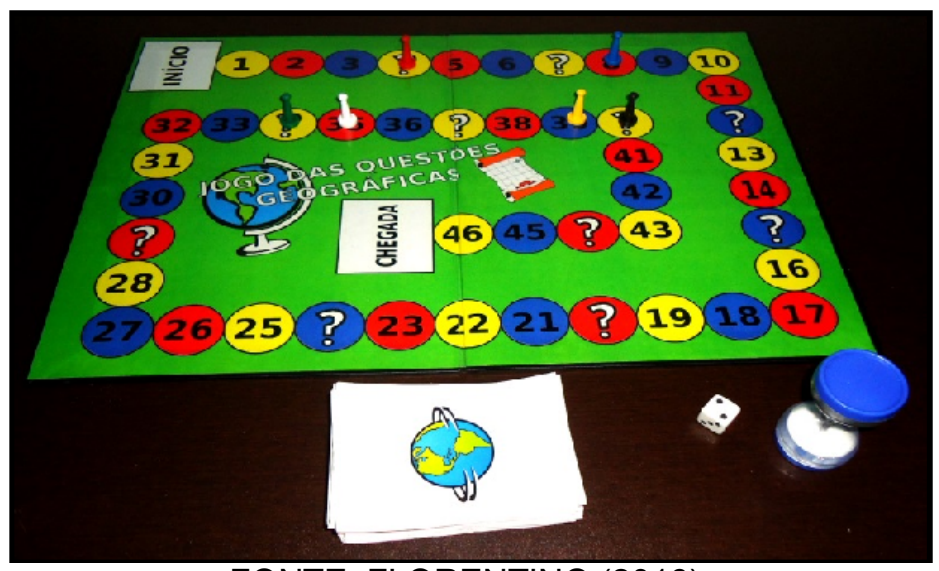

FONTE: FLORENTINO (2016).

O jogo contém um tabuleiro, seis peões de plástico, um dado numérico, uma ampulheta de plástico e 57 cartas com questões que se dividem em três níveis: a) respostas diretas; b) respostas indiretas, com alternativas; c) interpretação de figuras.

As atividades a serem desenvolvidas com este lúdico estão apoiadas no plano de aula exibido no Quadro 2 a seguir.

\section{QUADRO 2 - Plano de aula do jogo das Questões Geográficas}

\section{Turma: $1^{a}$ série do ensino médio.}

Duração da aula: 1 aula de 50 minutos.

Temas: Território; Economia; Geopolítica; Cartografia, Projeções Cartográficas; Geologia; Meio Ambiente; Recursos Hídricos; Continentes; Biodiversidade; Regiões Brasileiras; entre outros.

Competências e habilidades desenvolvidas: conhecer e aprender conceitos como: território; lugar; espaço; fenômenos naturais - como, quando e onde ocorrem; cartografia e suas características, projeções cartográficas, escala, orientação e coordenadas; paisagem; geopolítica; blocos econômicos; economia; entre outros.

Objetivos: contribuir para a construção do pensamento crítico nos alunos sobre: a presença e o papel da natureza e sua relação com a vida, na construção do espaço geográfico; a apropriação e a transformação dos territórios; o modo de produzir e pensar o mundo nas sociedades atuais. Ademais, discutir os grandes dilemas de diferentes fases da história, do trabalho, da cultura e das concepções de natureza, buscando compreender a Geografia sob uma perspectiva histórica ampliada.

Sequência Didática: 
Apresentação das regras e instruções do jogo pelo professor;

Organização da sala em grupos;

Distribuição e execução do jogo;

Avaliação: Analisar o desempenho e a participação das equipes no jogo.

FONTE: FLORENTINO (2016).

\section{O APRIMORAMENTO DO JOGO}

Nesta etapa, o protótipo foi aplicado em quatro turmas de $1^{\mathrm{a}}$ série do ensino médio: três em Rio Claro/SP e uma em São José dos Campos/SP.

$\mathrm{Na} 1^{\text {a }}$ série da Escola A, situada no município de São José dos Campos/SP, em junho de 2015, havia 29 alunos presentes, o professor e um auxiliar (Figura 2).

FIGURA 2 - Aplicação do jogo de tabuleiro na $1^{\text {a }}$ série do ensino médio da Escola A

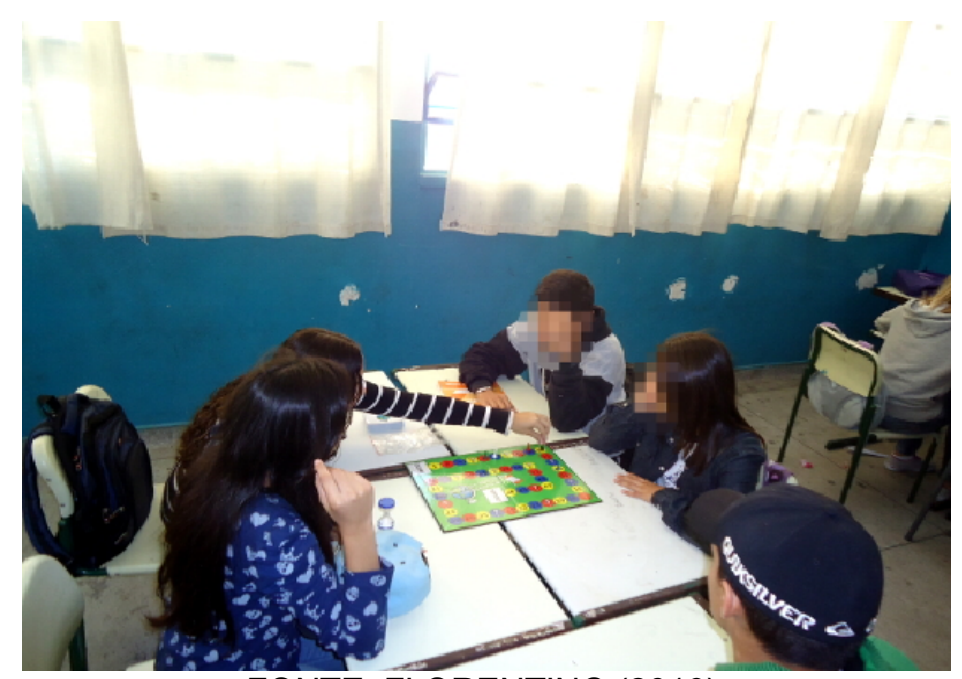

FONTE: FLORENTINO (2016).

O responsável pela classe afirmou, previamente, que o rendimento da turma era muito baixo, o que ficou comprovado durante a execução do jogo, pois os estudantes apresentavam dificuldades, inclusive, na leitura das cartas.

Foi interessante observar que, ainda assim, os companheiros que tinham menos dificuldade ajudavam os demais e contribuíam, então, para a conclusão do jogo de maneira correta, como aponta o Gráfico 1.

GRÁFICO 1 - Desempenho do $1^{\circ}$ ano da Escola A

Estudos Geográficos, Rio Claro, 16(1): 144-158, jan./jun. 2018 (ISSN 1678-698X) 


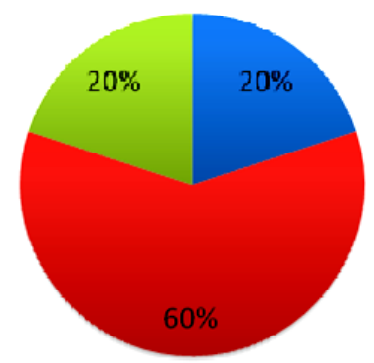

FONTE: FLORENTINO (2016).

Em suma, o rendimento da turma na partida foi mediano, apresentando $60 \%$ como bom e $20 \%$ como regular, que, neste caso, representa o grupo que não concluiu a dinâmica a tempo, como os demais. Apenas $20 \%$ obteve desempenho plenamente satisfatório, pois entendeu as regras e concluiu o jogo sem dificuldade.

Os demais possuíam grande defasagem, o que acresceu ainda mais complexidade ao jogo, que contém questões sobre diversos temas da Geografia, compondo uma revisão das séries anteriores.

Unidos, os estudantes ultrapassaram os obstáculos. Ao responder corretamente a uma questão, os escolares comemoravam alegremente e sentiam-se estimulados a continuar.

O jogo foi aplicado também em três turmas da Escola B, localizada em Rio Claro/SP, entre os meses de agosto e setembro de 2015.

Na turma I (Figura 3), a aceitação do material foi positiva. Estavam presentes 29 alunos, mais o docente. Logo após ouvir sobre a prévia da atividade, a turma se organizou em cinco grupos.

\section{FIGURA 3 - Aplicação do jogo de tabuleiro na turma I da Escola B}

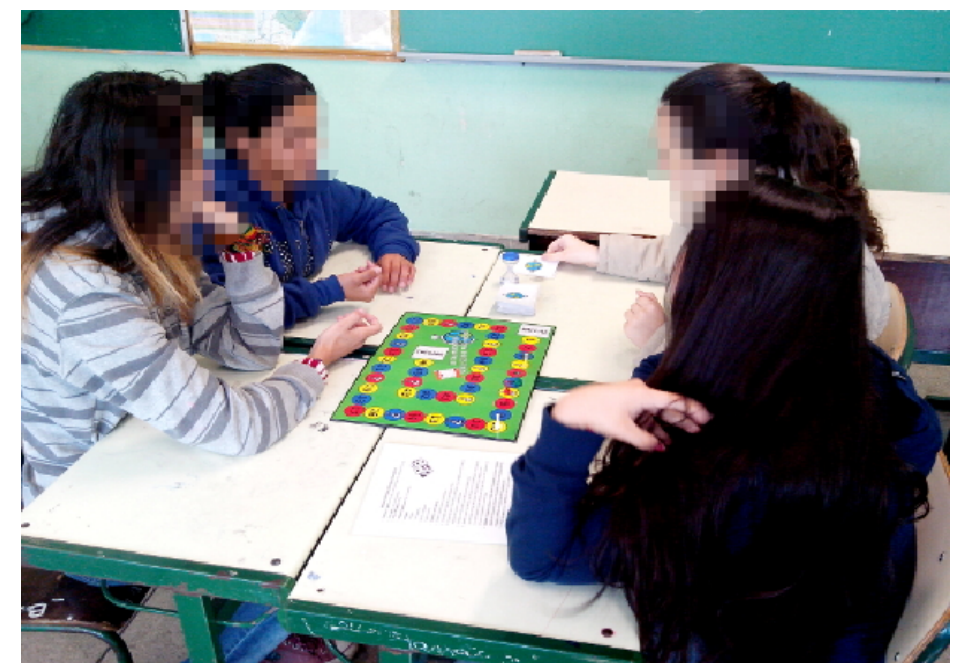

FONTE: FLORENTINO (2016). 
As equipes não manifestaram dúvidas em relação às regras e às instruções do jogo, apenas sobre as questões abordadas, mas isso fazia parte da dinâmica. Segundo o professor, o rendimento escolar geral da turma era muito baixo, porém até mesmo os estudantes que costumavam tumultuar as aulas se envolveram na atividade.

O desempenho da classe durante o jogo, como expõe o Gráfico 2, foi bastante satisfatório, apresentando um rendimento de $33 \%$ como ótimo e $50 \%$ como bom. Todos participaram e se empenharam para ver quem iria vencer a brincadeira.

\section{GRÁFICO 2 - Desempenho da turma I da Escola B. \\ -ÓTIMO $=B O M \quad$-REGULAR}

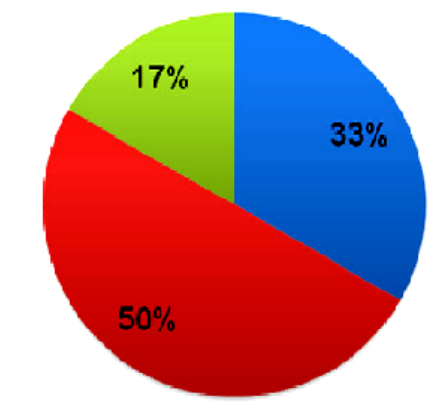

FONTE: FLORENTINO (2016).

A turma II (Figura 4) demonstrou ter apreciado muito a ideia do jogo, levantando elocuções como:

- Gostaria de poder levar esse jogo para casa.

Naquele dia, a classe possuía 25 escolares presentes e o educador.

FIGURA 4 - Aplicação do jogo de tabuleiro na turma II da Escola B.

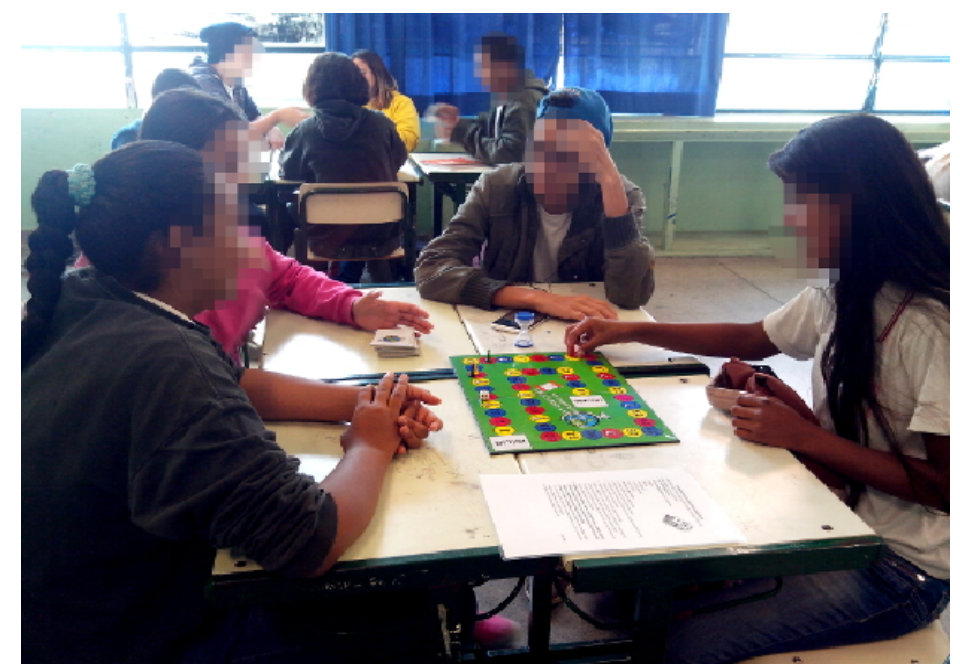

FONTE: FLORENTINO (2016). 
Os alunos ouviram com atenção a explanação das regras do jogo e, em seguida, dividiram-se em cinco equipes.

O responsável pela turma foi muito atencioso, participou de muitas jogadas ao lado dos alunos, importando-se e analisando as dúvidas que os estudantes demonstravam durante a brincadeira.

Esta turma obteve os resultados exibidos no Gráfico 3, onde os estudantes apresentaram um rendimento de $60 \%$ considerado bom, $20 \%$ ótimo e $20 \%$ regular.

\section{GRÁFICO 3 - Desempenho da turma II da Escola B}

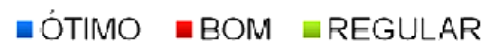

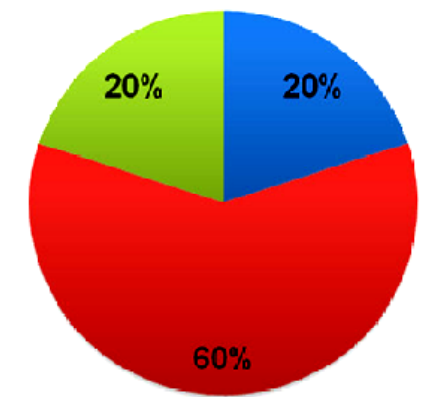

FONTE: FLORENTINO (2016).

Na última aplicação do jogo de tabuleiro, na turma III (Figura 5), o educador adiantou que a classe possuía desempenho melhor que a turma II, e isso se refletiu no desenvolvimento da atividade, momento em que os alunos apresentaram a seguinte performance (Gráfico 4).

FIGURA 5 - Aplicação do jogo de tabuleiro na turma III da Escola B

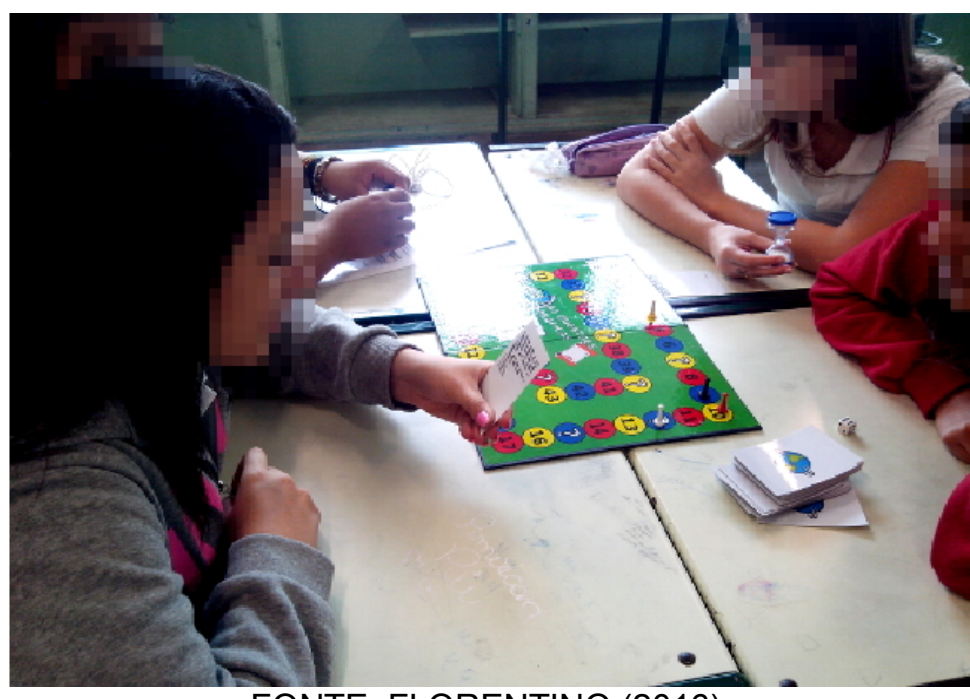

FONTE: FLORENTINO (2016).

Estudos Geográficos, Rio Claro, 16(1): 144-158, jan./jun. 2018 (ISSN 1678 — 698X) 


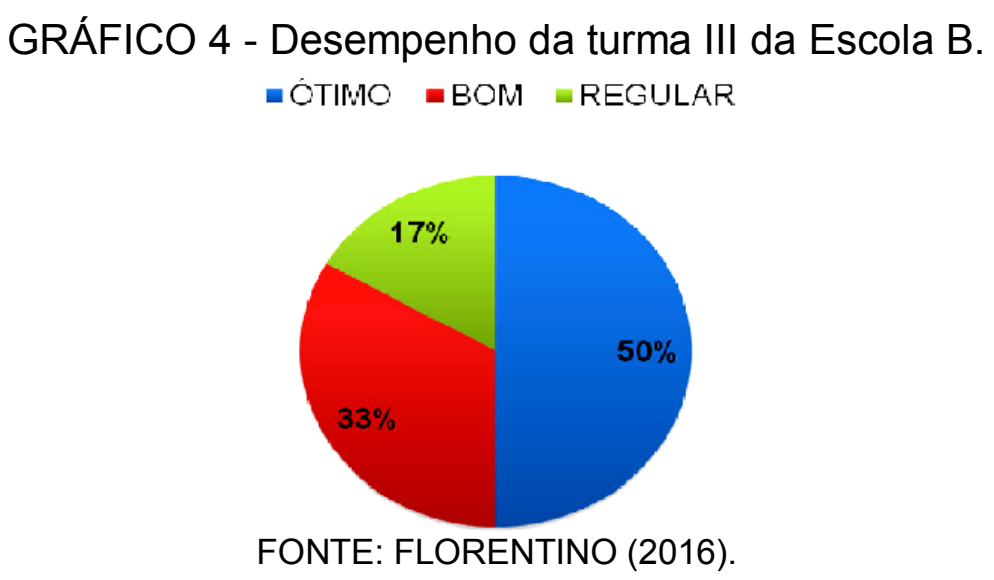

A turma III foi muito receptiva e educada, concluiu o exercício em uma perspectiva construtiva e divertida, sempre demonstrando bastante interesse pela dinâmica, o que refletiu no desempenho da classe, que apresentou rendimento de $50 \%$ como ótimo, $33 \%$ bom e apenas $17 \%$ regular.

Alguns estudantes questionaram, ainda, quanto custou e aonde poderiam comprar o jogo, além de terem curiosidade em saber como ele foi elaborado.

\section{A ANÁLISE CRÍTICA DO JOGO FEITA PELOS PROFESSORES}

O jogo foi aplicado na turma de três professores, sendo que, desses três profissionais, dois consideraram o jogo ótimo e um considerou bom. Mesmo assim, todos afirmaram ser uma boa alternativa para trabalhar a interatividade, o raciocínio lógico, a dinâmica e o companheirismo entre os escolares, contribuindo para a lembrança dos conteúdos do ensino fundamental.

Ademais, os educadores destacaram que gostaram de ver como os alunos interagiram durante o jogo, um ajudando o outro, fato que, segundo eles, não ocorre com frequência; o que enriqueceu o companheirismo, a paciência e o respeito às regras.

\section{A OFICINA}

A experiência, inserida no Encontro Lívia de Oliveira: Cartografia Escolar e Ensino de Geografia, teve duração de quatro horas e foi realizada no Departamento de Geografia, do Instituto de Geociências e Ciências Exatas da UNESP, Campus de Rio Claro.

Contou com a presença de quatorze participantes, dentre eles, professores da rede básica de ensino e alunos de licenciatura em Geografia da instituição.

Inicialmente, foi realizada uma breve apresentação dos elementos sobreditos que culminaram na elaboração da proposta do jogo de tabuleiro.

Para tanto, argumentos como: ensinar os alunos a respeitarem as regras, os limites, os colegas; permitir a socialização, estreitar laços, construir pensamentos e ideias juntos; desinibir os participantes e os envolver em uma competição saudável; 
diversão para qualquer idade; entre outros, foram cruciais para que os integrantes compreendessem a razão da escolha deste lúdico.

Somado a isso, exibiram-se as semelhanças e divergências entre o jogo e a aplicação de exercícios teóricos, ilustrado a seguir no Quadro 3.

Quadro 3: Semelhanças e divergências entre o jogo e os métodos tradicionais de ensino

\begin{tabular}{|c|c|c|}
\hline \multirow{3}{*}{ Semelhanças } & Jogo & $\begin{array}{l}\text { Aplicação de Exercícios - } \\
\text { Método Tradicional }\end{array}$ \\
\hline & Desenvolve competências e habilidades. & Desenvolve competências e habilidades. \\
\hline & É um desafio. & É um desafio. \\
\hline \multirow{4}{*}{ Divergências } & $\begin{array}{l}\text { Método pouco utilizado nas aulas de } \\
\text { Geografia. } \\
\text { Quando usado, torna as aulas atraentes por } \\
\text { causa do "novo", do "diferente". }\end{array}$ & $\begin{array}{l}\text { Por ser um método tradicional de ensino é, } \\
\text { então, comum, conhecido, cotidiano. }\end{array}$ \\
\hline & A interação deste exercício é coletiva. & A interação deste exercício é individual. \\
\hline & $\begin{array}{c}\text { Envolve diversão, brincadeira, descontração } \\
\text { e espontaneidade. }\end{array}$ & Envolve apenas os conteúdos de ensino. \\
\hline & $\begin{array}{l}\text { A fixação do conteúdo é naturalmente } \\
\text { espontânea, ocorrendo ao longo do jogo. }\end{array}$ & $\begin{array}{l}\text { A fixação ocorre, comumente, por meio de } \\
\text { memorização. }\end{array}$ \\
\hline
\end{tabular}

FONTE: FLORENTINO (2016).

Para sustentar tal argumentação, utilizou-se autores como Macedo, Petty e Passos (2005), Jacquin (1960), Chateau (1954), Murcia (2005), que defendem o uso do jogo como uma estratégia riquíssima para o ensino.

Murcia (2005), por exemplo, afirma que:

Mediante o jogo, a criança aprende normas de comportamento para crescer e aprender a viver na sociedade de forma integral. O jogo fomenta a capacidade para a elaboração de normas da infância à vida adulta. A criança cresce aprendendo hábitos de convivência necessários para viver em sociedade. $O$ jogo proporciona ao ser humano um interesse pelo conhecimento, uma atitude ativa, positiva e crítica, que lhe permite se integrar de maneira gradual na família, na escola e na vida (MURCIA, J. A. M., 2005, p. 27).

Após a explanação das bases teóricas, foi apresentado, também, o passo a passo da elaboração do jogo, bem como as regras e instruções do mesmo (Figura $6)$. 
Figura 6: Apresentação do jogo de tabuleiro "Questões Geográficas"

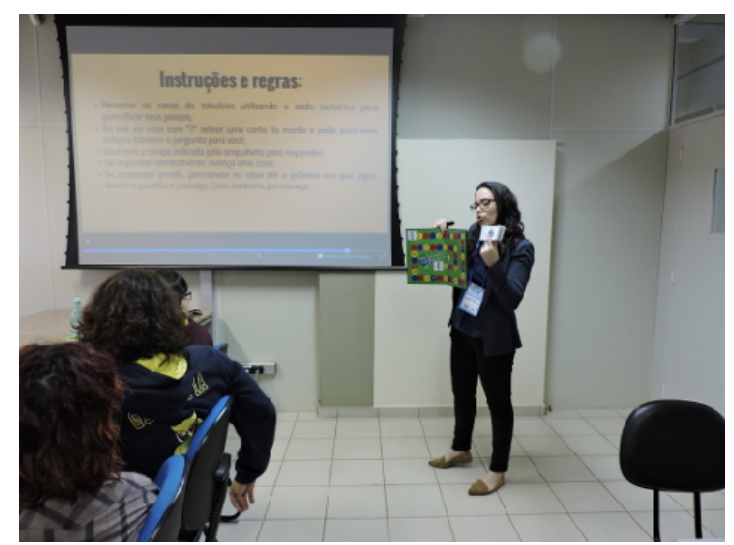

FONTE: acervo próprio.

Sendo um instrumento diagnóstico, o jogo das Questões Geográficas retoma assuntos do ensino fundamental até o médio, trazendo perguntas simples e também as mais complexas sobre: Geopolítica, Cartografia, Geologia, Meio Ambiente, Recursos Hídricos, Economia, Biodiversidade, entre outros.

Para realizar a aplicação do jogo (Figuras 7 e 8), solicitou-se que os participantes se dividissem em três grupos, sendo um composto por quatro integrantes e os demais por cinco.

Figura 7 e 8: Participantes do curso com o jogo
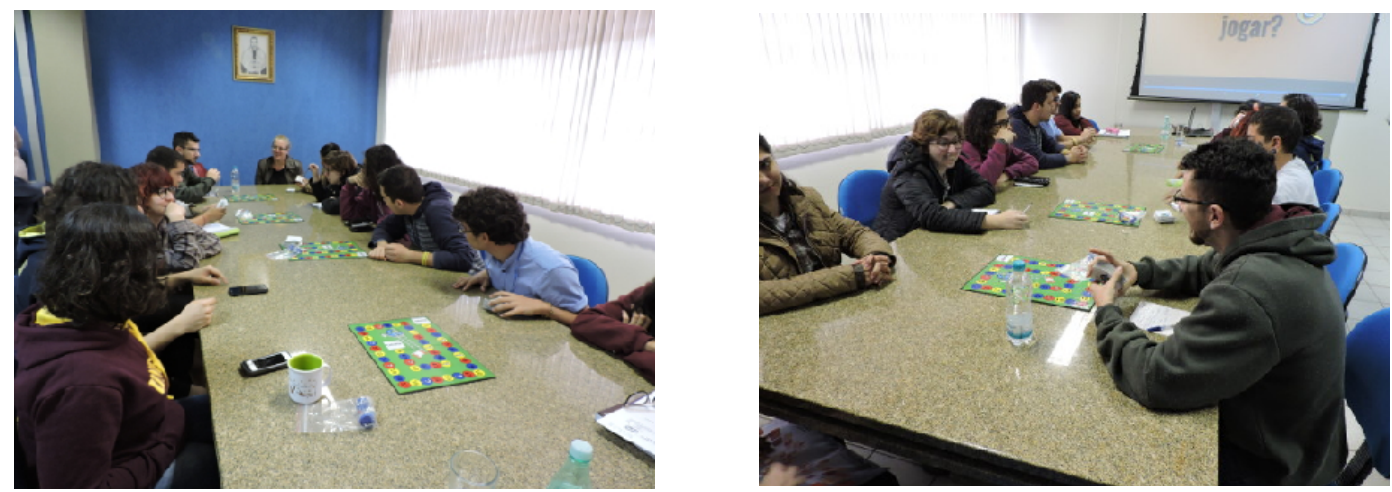

FONTE: acervo próprio.

Ao longo da dinâmica foi possível notar que todos entenderam as regras e conseguiram concluir a dinâmica com facilidade. Ao final, deram sugestões e críticas ao jogo e sobre o curso, apresentando propostas de como enriquecer a prática utilizando mais cartas com questões e representações gráficas, como os mapas temáticos, aumentando a quantidade e a variedade de ambos.

Para finalizar o curso, sugeriu-se aos participantes que aplicassem a experiência da oficina com as suas turmas, de modo que eles elaborassem, de forma colaborativa com os alunos, um jogo, solicitando, para tanto, que, ao final de cada conteúdo, os estudantes pesquisassem uma ou mais questões relacionadas àquele tema. Assim, ao final do semestre, as cartas seriam elaboradas com estas perguntas. 
Os escolares também seriam responsáveis pela arte do tabuleiro em folha sulfite A4 ou A3, visando agregar a criatividade dos estudantes à elaboração do material, para que, posteriormente, as cartas e este tabuleiro compusessem um jogo.

Os peões podem ser feitos com materiais facilmente encontrados em casa, como: tampa de garrafa PET, caixa de fósforo vazia, entre outros.

Propõe-se, ainda, que estes jogos sejam aplicados numa dinâmica entre os grupos da turma ou entre as classes da escola.

\section{CONSIDERAÇÕES FINAIS}

Desejou-se destacar neste artigo o jogo de tabuleiro como uma possibilidade lúdica de expor aos alunos os temas da Geografia, levando-os a compreender na prática o conteúdo explanado nas aulas teóricas.

Autores como Lopes (2002, p. 22) defendem o uso do jogo no ensino, ao afirmar que "se os conteúdos programáticos tiverem uma aplicabilidade prática, terão maior probabilidade de serem apreendidos do que as teorias soltas e muitas vezes transmitidas de maneira incompreensível e desestimulante".

Sendo assim, explorou-se no jogo de tabuleiro uma maneira divertida e, também, prática de se ensinar.

Este lúdico é capaz de tornar a aula mais prazerosa e, simultaneamente, pode dar significado aos estudantes dos conceitos científicos, como aponta Castellar (2011):

Desde o final da década de 90 do século 20, os autores que discutem questões de metodologia e didática no ensino de Geografia têm realçado a importância de promover atividades em sala de aula que levem os alunos a darem significado aos conceitos científicos (CASTELLAR, S., 2011, p. 249).

Contudo, compreende-se que o uso deste jogo é uma alternativa valiosa, pois a aplicação do material, tanto nas escolas como na oficina, obtiveram uma avaliação significativamente positiva.

Sendo assim, tanto na infância, como na vida adulta, aprender através do jogo promove, simultaneamente, a socialização e o entretenimento. Lopes (2002) apoia essa ideia ao dizer que:

É muito mais fácil e eficiente aprender por meio de jogos, e isso é válido para todas as idades, desde o maternal até a fase adulta. $\mathrm{O}$ jogo em si possui componentes do cotidiano e o envolvimento desperta o interesse do aprendiz, que se torna sujeito ativo do processo (LOPES, M. G., 2002, p. 23).

Murcia (2005, p. 16) concorda com a afirmação e também apoia o uso do jogo como uma metodologia alternativa, que contribui no processo de ensinoaprendizagem, ao defender que "o ser humano necessita permanentemente de entusiasmo, da seriedade e da alegria. Tudo isso pode ser proporcionado pelas vivências do jogo: um enriquecimento integral, em suas distintas formas". 
Portanto, com base nas reflexões apresentadas neste artigo, propõe-se que o ensino de Geografia pode ser potencializado com a inserção de alternativas metodológicas como o jogo de tabuleiro.

\section{REFERÊNCIAS BIBLIOGRÁFICAS}

BRASIL. Secretaria de Educação Fundamental. Parâmetros curriculares nacionais: geografia. Brasília: MEC/SEF, 1998.

CASTELLAR, S. M. V. Educação geográfica: a psicogenética e o conhecimento escolar. Cad. Cedes, Campinas, 2006.

. A cartografia e a construção do conhecimento em contexto escolar. In: ALMEIDA, Rosângela Doin de. Novos rumos da cartografia escolar: currículo, linguagens e tecnologia. São Paulo: Contexto, 2011. p. 121-136.121

CHATEAU, J. O jogo e a criança. Trad. Guido de Almeida. São Paulo: Summus Editorial, 3 ed. 1954. 139 p.

FRANCO, L. C. P. Jogos digitais educacionais nas aulas de Educação Física: Olympia, um videogame sobre os Jogos Olímpicos. Tese de Doutorado. Instituto de Biociências. Universidade Estadual Paulista, UNESP. Rio Claro, 2014. 166 p.

GOTTARDI, R. B. O jogo como elemento no desenvolvimento da criança. Revista Educação, v. 4, n. 1, p. 98-102, 2009.

JACQUIN, G. A educação pelo jogo. Paris: Gleurus, 1960, 228 p.

. A educação pelo jogo. São Paulo: Flamboyant, 1963.

LOPES, M. G. Jogos na educação: criar, fazer, jogar. São Paulo: Cortez, 2002.

LOPES, O. R. Jogo "Ciclo das rochas": um recurso lúdico para o ensino de Geociências. Dissertação (Mestrado). Universidade Estadual de Campinas. Instituto de Geociências. Campinas, SP. 2007. 139 p.

MACEDO, Lino de; PETTY, Ana Lúcia Sícoli; PASSOS, Norimar Christe. Os jogos e o lúdico na aprendizagem escolar. Porto Alegre: Artmed, 2005.

MARCATO, D. C. G. O design nos jogos geométricos aplicados ao ensino infantil. Dissertação (Mestrado). Faculdade de Arquitetura, Artes e Comunicação. Universidade Estadual Paulista, UNESP. Bauru, 2009. 159 p.

MIANI, Camila Sanches. Ensino de biodiversidade: análise do conceito em manuais didáticos e proposição de jogo digital educativo. 2013. $102 f$. 
Dissertação (Mestrado em Educação para a Ciência) - UNESP, Faculdade de Ciências, Bauru, 2013.

MURCIA, Juan Antonio Moreno. Aprendizagem através dos jogos. Trad. Valério Campos. Porto Alegre: Artmed, 2005.

ROSA, M. Role Playing Game Eletrônico: uma tecnologia lúdica para aprender e ensinar Matemática. Dissertação (Mestrado em Educação Matemática). Instituto de Geociências e Ciências Exatas. Universidade Estadual Paulista, UNESP. Rio Claro, 2004. 184 p.

SANTANA. E. M. de. O Uso do Jogo Autódromo Alquímico como mediador da aprendizagem no Ensino de Química. Dissertação de Mestrado. Instituto de Biociências, Faculdade de Educação. Universidade de São Paulo, USP. São Paulo, 2012. $172 \mathrm{p}$.

SDOUKOS, S. S. Avaliação do desempenho de escolares em um jogo educativo de habilidades monetárias. Dissertação de Mestrado. Centro de Ciências Biológicas. Universidade Estadual de Londrina. Londrina, Paraná. 2012. 79 p.

SILVA, M. C. R. G. P. da. Jogos educativos 3d no ensino da Física e da Química: um estudo com alunos do 7 ano de escolaridade. Dissertação de Mestrado. Universidade Lusófona de Humanidades e Tecnologias. Faculdade de Engenharia. Lisboa, Portugal. 2014. 74 p.

SOUKEFF, F. E. B. Jogo Mega-Duque: uma proposta para o ensino de probabilidade. Dissertação (Mestrado profissional). Instituto de Biociências, Letras e Ciências Exatas. Universidade Estadual Paulista "Júlio de Mesquita Filho", UNESP. São José do Rio Preto, 201478 f.

SÃO PAULO (Estado). Secretaria da Educação. Proposta Curricular do Estado de São Paulo: Geografia - Ensino Fundamental Ciclo II e Ensino Médio. São Paulo: SEE, 2008.

VILLAS BÔAS, M. C. Construção da noção de número na Educação Infantil: Jogos como recurso metodológico. Dissertação de Mestrado. Faculdade de Educação. Universidade de São Paulo, USP. 2007. 129 p.

YIN, R. K. Estudo de caso: planejamento e métodos. Trad. Daniel Grassi. 2.ed. Porto Alegre: Bookman, 2001. 